\title{
Synthesis of Copper Nanoparticles Using Chromolaena odorata (L.) Leaf Extract as A Stabilizing Agent
}

\author{
Suprapto Suprapto*, Cantika Alda Hafshah Handoyo, Putri Ayu Senja, Veto Barid Ramadhan, \\ Yatim Lailun Ni'mah \\ Department of Chemistry, Institut Teknologi Sepuluh Nopember, Surabaya, Indonesia \\ - email: suprapto19@gmail.com \\ DOI : 10.20885/ijca.vol3.iss1 .art2
}

\begin{tabular}{l} 
ARTICLE INFO \\
\hline Received : 17 February 2020 \\
Revised : 22 February 2020 \\
Published : 15 March 2020 \\
Keywords : copper, nanoparticles, \\
chromolaena odorata
\end{tabular}

\begin{abstract}
The synthesis of copper nanoparticles (CuNPs) by chemical reduction had been carried out. In this study, the synthesis of copper nanoparticles was carried out using Sentalo leaf extract (Chromolaena odorata (L.)) as a stabilizing agent and sodium citrate as a reducing agent. The extraction of Sentalo leaves was done using aqua demineralization as a solvent. The extraction was carried out at $60^{\circ} \mathrm{C}$ and stirred for 45 minutes. The CuSO 4 concentrations $(0.05 \mathrm{M} ; 0.1 \mathrm{M}$; and $0.15 \mathrm{M})$, sodium citrate concentrations $(0.15 \mathrm{M} ; 0.2 \mathrm{M}$; and $0.25 \mathrm{M})$, and Sentalo extract $(10 \%, 20 \%$, and $30 \%)$ were optimized. The copper nanoparticles that synthesized were in the form of brownish-green powder. The nanoparticles were characterized using FTIR, XRD, PSA, and TEM. The XRD diffractogram shows peaks at $2 \theta=43.15^{\circ} ; 49.75^{\circ}$; and $73.91^{\circ}$ with a small intensity. Copper nanoparticles that synthesized have stem shapes with an average diameter of $30 \mathrm{~nm}$. Optimization by using Surface Response Methodology with BoxBehnken Design shows optimal parameter for absorption at 300 $\mathrm{nm}$ with $\mathrm{CuSO} 4$ concentrations of $0.12 \mathrm{M}$ to $0.15 \mathrm{M}$, sodium citrate concentrations of $0.22 \mathrm{M}$ to $0.25 \mathrm{M}$, and percent extract of $5 \%$ to $30 \%$. Optimization parameters for absorption at $800 \mathrm{~nm}$ was obtained using CuSO4 concentration of $0.05 \mathrm{M}$ to $0.06 \mathrm{M}$, sodium citrate concentration of $0.15 \mathrm{M}$ to $0.25 \mathrm{M}$, and the percent extract of $10 \%$ to $22.5 \%$.
\end{abstract}

\section{INTRODUCTION}

Nanotechnology has become fastest-growing study in the world of science and technology. It is the most capable technology that can be applied at almost all fields such as biomedical, antibacterial, catalytic, optical, and electrical [1]. Nanoparticles have distinctive properties compared to large materials. Nanoparticles have the ability to penetrate the physiological barrier and can circulate in the physiological system of living beings [2]. Nanoparticles generally have a size below $100 \mathrm{~nm}$ [3]. There were two approaches to obtain nanoparticles, top-down and bottomup approach. The top-down approach was carried out by reducing the size of the initially large particle. The bottom up approach was done by increasing the size of particulate up to the nanometer size [4]. One of the metal nanoparticles currently developed is copper. Copper is one of the metals that has a reasonably cheap and abundant. The formation of copper nanoparticles with a bottom-up approach was one of the methods that often used in the research. The advantage of this approach was that the nanoparticle size can be adjusted according to the desired usability. Control of such measures can be done in several ways i.e. by regulating the concentration of precursors [4].

In the synthesis of CuNPs, there are several parameters to be considered i.e. temperature, reaction time, reducing agent, type of precursors, concentration as well as its mixing, nucleation effect, growth, agglomeration, and nanoparticles distribution [5]. Copper was metal that WILL BE oxidized when contact with air. Therefore, the presence of reducing and stabilizing agent in the synthesis of CuNPs was required. There are several methods used in the synthesis of CuNPs, namely chemical methods, physical methods, biological methods and green synthesis [6]. Some research suggests that 
plant extracts can be used as reducing agent and stabilizing agents on CuNPs synthesis. The use of plant extracts as a reducing agent or stabilizing agents has a purpose to reduce the use of toxic chemicals in the synthesis due to the nature of the environmentally friendly plant extracts. Plant extracts have been applied in the synthesis of copper nanoparticles i.e. Passiflora Foetida [7], Portulaca oleracea [8], and Syzgium Fondini [1]. The chemical contained in plants generally: steroids, alkaloids, saponins, terpenoids, flavonoids [9]. Biomolecules such as flavonoids and terpenoids can act as reducing agents for metal ions and stabilizing agent to minimize agglomeration of nanoparticles [10]. The C. Odorata (L.) plant extract has not been used in the research of copper nanoparticles. The chemical compounds contained in the Sentalo leaves include tannins, saponins, steroids, terpenoids, and flavonoids [11]. C. Odorata (L.) plant is a wild plant and still not utilized optimally for research [12]. In this study, the synthesis of copper nanoparticles was carried out using C. Odorata (L.) leaf extract as stabilizing agent. The C. odorata (L.) was obtained from Sumbawa, West Nusa Tenggara. The synthesis of copper nanoparticles was carried out by reacting a solution of copper (II) sulfate $\left(\mathrm{CuSO}_{4}\right)$ with a C. Odorata (L.) leaf extract

\section{METHOD}

\subsection{Materials and Tools}

The instruments that used in this research were the laboratory glassware, analytical balance, magnetic stirrer, hot plate, spray bottle, UV-Vis Spectrophotometer (Genesys 10S), FTIR (Shimadzu Instrument Spectrum One 8400s), XRD (X'Pert MPD), PSA Zetasizer (Nano ZS), and TEM (HT7700). Whatman filter paper. The materials that used in this study were copper (II) sulfate pentahydrate $\left(\mathrm{CuSO}_{4} \cdot 5 \mathrm{H}_{2} \mathrm{O}\right.$ (Sigma-Aldrich)) was used as a precursor salt, trisodium citrate $\left(\mathrm{Na}_{3} \mathrm{C}_{6} \mathrm{H}_{5} \mathrm{O}_{7}\right.$ (Sigma-Aldrich)) as reducing agent and C. odorata (L.) leaves were collected from Sumbawa, NTB, Indonesia. Deionized water was used throughout this study.

\subsection{Preparation of the Extract}

Fresh leaves of C. odorata (L.) were rinsed thoroughly 2-3 times with deionized water to remove dust and unwanted particles. Leaves were dried in an oven at $50{ }^{\circ} \mathrm{C}$. The small pieces of $\mathrm{C}$. odorata (L.) leaves were dissolved in deionized water (10, 20, and 30 grams of small pieces of Sentalo leaves were dissolved in $100 \mathrm{~mL}$ deionized water). The solution was mixed with a magnetic stirrer at $60^{\circ} \mathrm{C}$ for 45 minutes. The leaf broth was filtered twice through a Whatman filter and stored at $4^{\circ} \mathrm{C}$ e for further experiments.

\subsection{Optimization of The Copper Nanoparticles Synthesis}

$\mathrm{CuSO}_{4}(0.05 ; 0.1 ; 0.15 \mathrm{M})$ was stirred while C. odorata (L.) extract $(10 \%, 20 \%$, dan $30 \%)$ were added dropwise to this solution. $\mathrm{Na}_{3} \mathrm{C}_{6} \mathrm{H}_{5} \mathrm{O}_{7}(0.15 ; 0.2 ; 0.25 \mathrm{M})$ was added to this solution. The solution was allowed to settle for 24 hours in a dark room. The discoloration that occurs in the solution was observed using UV-Vis spectrophotometers.

\section{RESULT AND DISCUSSION}

\section{Characterization of materials}

FTIR spectra of C. odorata leaf extract and CuNPs were shown in Figure 1. Figure 1a was the spectrum of C. odorata (L.) extract that shows a peak at $3435 \mathrm{~cm}-1$ which was a typical absorption of $\mathrm{OH}$ groups stretching. The absorption peak at $1641 \mathrm{~cm}-1$ showed the typical of $\mathrm{C}=\mathrm{C}$ groups. the absorption peak at $1027 \mathrm{~cm}-1$ showed the presence of C-O groups. FTIR spectra of copper nanoparticles (CuNPs) (Figure 1b) shows peaks at $3445 \mathrm{~cm}-1,2926 \mathrm{~cm}-1,1634 \mathrm{~cm}-1,1393 \mathrm{~cm}-1$, and $1074 \mathrm{~cm}-1$ where each indicates the presence of $\mathrm{OH}, \mathrm{C}-\mathrm{H}$ alkane, $\mathrm{C}=\mathrm{C}, \mathrm{CH}$, and $\mathrm{C}-\mathrm{O}$ groups. The peak at $1393 \mathrm{~cm}-1$, indicating the existence of $\mathrm{C}=\mathrm{C}$ stretching, indicating the occurrence of coordination of copper nanoparticles [13]. 


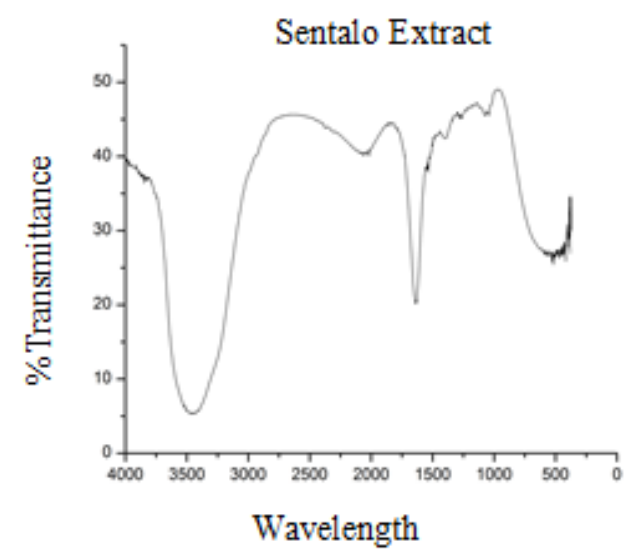

(a)

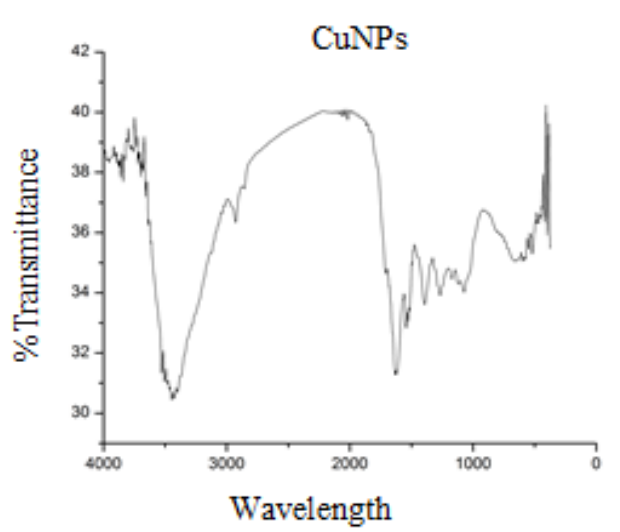

(b)

Figure 1. FTIR spectra of (A) C. odorata leaf extract and (B) CuNPs

The CuNPs that synthesized was measured using UV-Vis spectrophotometers. UV-Vis spectra give useful information of nanoparticles due to peak position and the shape was sensitive to particle size [5]. In the UV-Vis spectra, the C. odorata extract solution indicates a peak at a wavelength of $300 \mathrm{~nm}$. The CuSO4 solution spectrum shows peaks at $815 \mathrm{~nm}$. Absorption band for CuNPs has been reported in the range of 250-450 $\mathrm{nm}$ [14]. In this study, the maximum peak of a synthesized solution showed maximum absorption at $305 \mathrm{~nm}$.

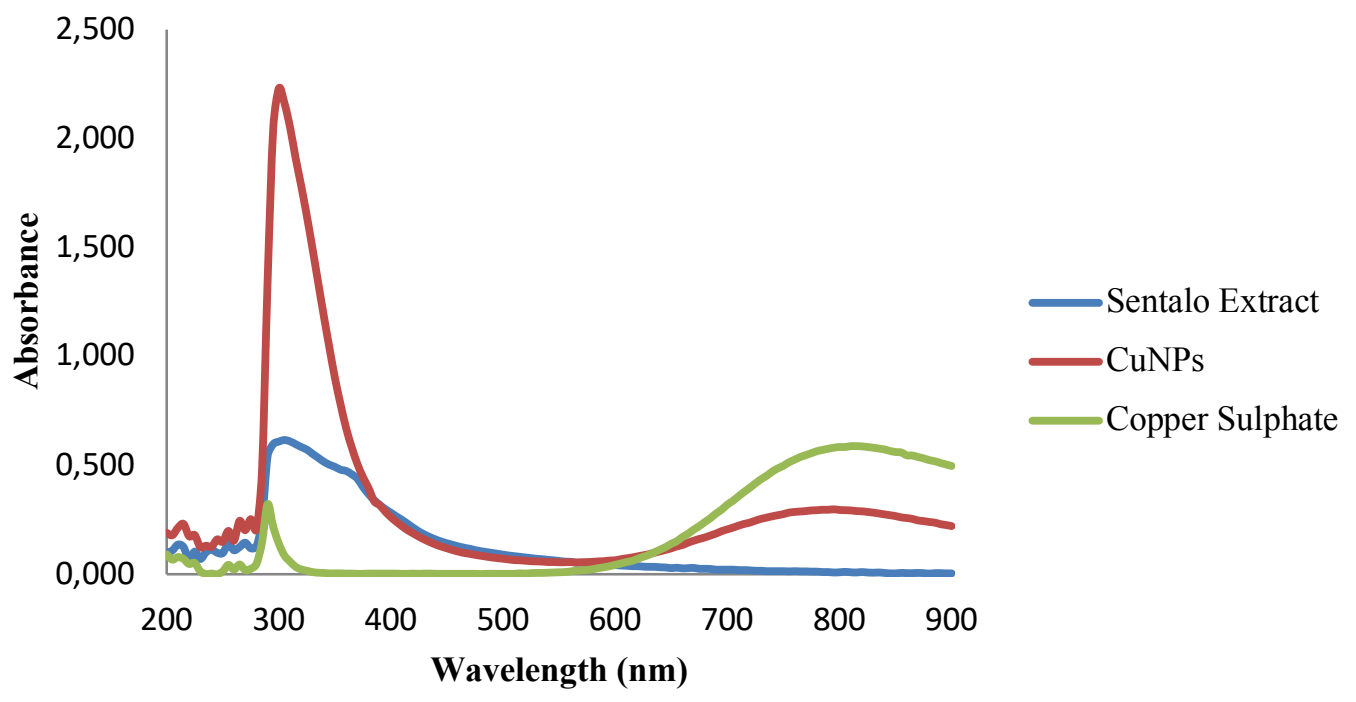

Figure 2. UV-Vis Spectrum of copper sulphate, CuNPS, and sentalo extracted

Figure 2 shows that the spectra of C. odorata extract, copper sulfate solution, and CuNPs. The peak at $305 \mathrm{~nm}$ and $785 \mathrm{~nm}$ was increase and decrease as the solution were mixed. Synthesis of copper nanoparticles indicates that there was an interaction between the $\mathrm{CuSO} 4$ solution and the $\mathrm{C}$. odorata leaf extract to form particulates. Particulates will dissipate UV-Vis ligth. It is in accordance with the Dynamic Light Scattering (DLS) method in which the rays that are dissipated by the particulate were equal in size to the wavelength that scattered [15].

The chemical structure of CuNPs was characterized using X-Ray Powder Diffraction (XRD). The diffractogram of CuNPs with C. odorata leaf extracts can be seen in Figure 3. CuNPs Synthesized using Azadirachta indica leaf extracts [10], shows peaks at $2 \theta=43.5^{\circ} ; 49.9^{\circ}$; and $74.01^{\circ}$. The difaktogram in Figure 3 shows the presence of peaks almost similar to the peak of CuNPs that synthsized using Azadirachta indica leaf extract which has peaks at $2 \theta=43.15^{\circ} ; 49.75^{\circ}$; and $73.91^{\circ}$ 
with a small intensity. The Diffactogram shows the formation of $\mathrm{CuO}$. $\mathrm{CuO}$ formation was caused by sample preparation by heating the suspension before XRD characterization.

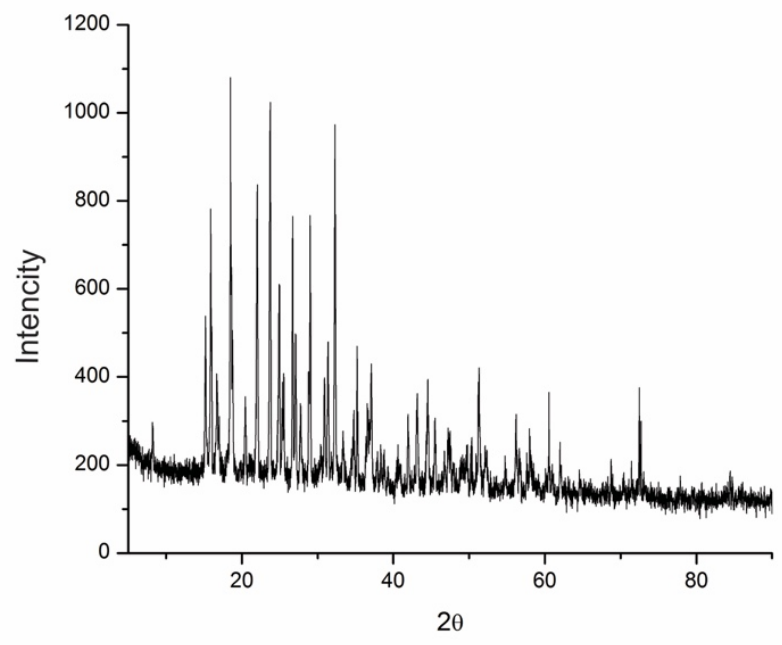

Figure 3. Diffactogram of CuNPs

Particle Size Analyzer (PSA) was applied to determine the particle size distribution and the average particle size of CuNPs. Particle distribution of CuNPs was presented in Figure 4. The size of CuNPs that have been synthesized was distributed from $28.21 \mathrm{~nm}$ to $255 \mathrm{~nm}$. In general, nanoparticles have a size of 1-100 nm. However, some literature indicates that nanoparticles can have a size of 1-1000 $\mathrm{nm}[6]$. CuNPs that have been synthesized using L-ascorbic acid have size distribution from 17.73 $\mathrm{nm}$ to $165.2 \mathrm{~nm}[13]$.

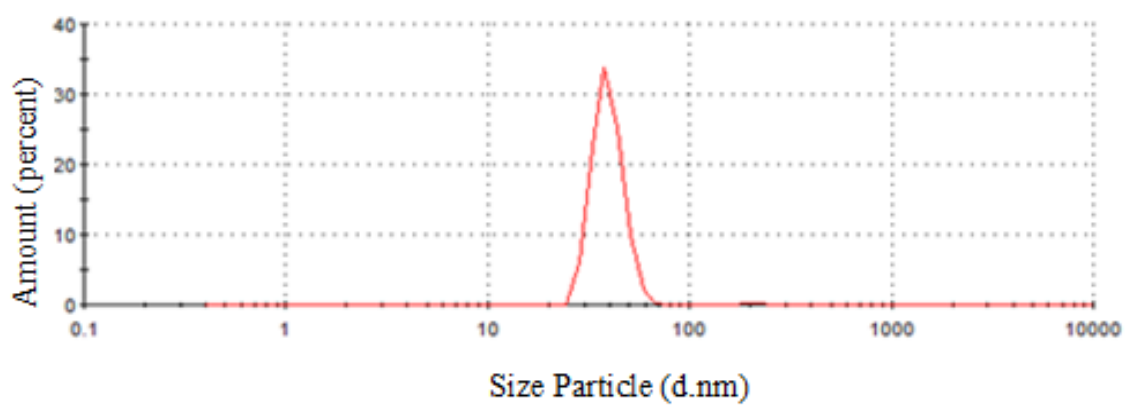

Figure 4. Histogram Size of CuNPs

The Transmission Electron Microscope (TEM) characterization of CuNPs was shown in Figure 5. The synthesized CuNPs have rod-shaped and has a particle size with a length of $260 \mathrm{~nm}$ and a width of $30 \mathrm{~nm}$. The TEM image shows a thin layer of the particle, which indicates the presence of a C. odorata extract as a capping agent. In another study, copper nanoparticle particles have a rod shape with a particle size where the length of $700 \mathrm{~nm}$ and a width of $100 \mathrm{~nm}$ [16]. 


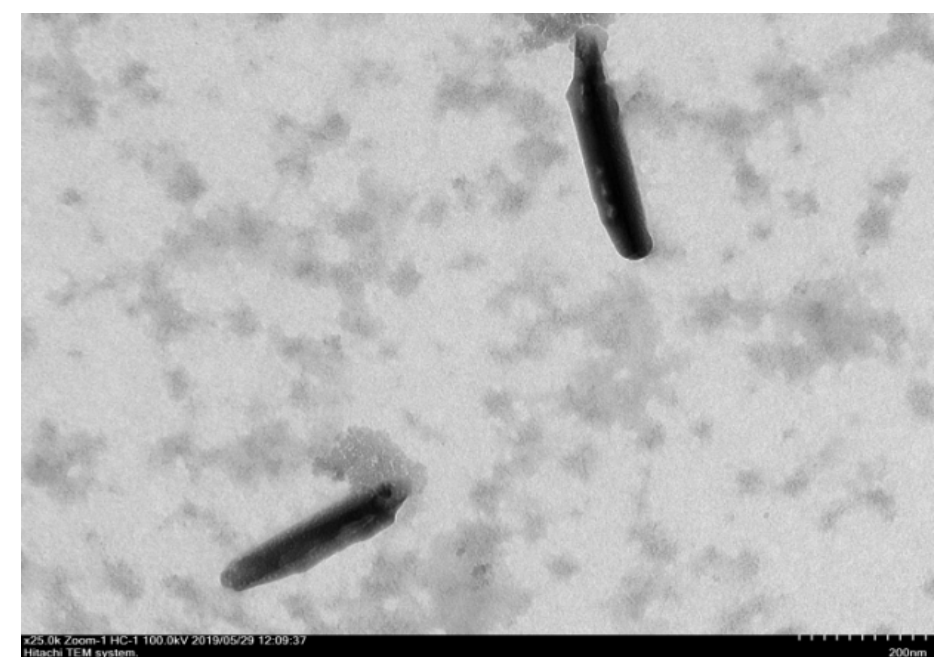

Figure 5. TEM of CuNPs with 25 times Magnification with Bar Scale $=20 \mathrm{~nm}$

\section{Optimization of CuNPs with Response Surface Methode (RSM) Box-Behnken Design}

Optimization of CuNPs synthesis was carried out using Surface Response Methodology with Box-Behnken Design. $\mathrm{CuSO}_{4}$ concentration, $\mathrm{Na}_{3} \mathrm{C}_{6} \mathrm{H}_{5} \mathrm{O}_{7}$ concentration, and percent extract was optimized. The input variables of optimized parameters were shown in Tabel 1.

TABLE I. Input Variables of RSM Optimization

\begin{tabular}{cccc}
\hline Variations & {$\left[\mathbf{C u S O} \mathbf{S}_{4}\right]$} & {$\left[\mathbf{N a}_{\mathbf{3}} \mathbf{C}_{\mathbf{6}} \mathbf{H}_{5} \mathbf{O}_{7}\right]$} & \%Ekstrak \\
\hline$(-1,-1,0)$ & 0.05 & 0.15 & 20 \\
$(1,-1,0)$ & 0.15 & 0.15 & 20 \\
$(-1,1,0)$ & 0.05 & 0.25 & 20 \\
$(1,1,0)$ & 0.15 & 0.25 & 20 \\
$(-1,0,-1)$ & 0.05 & 0.2 & 10 \\
$(1,0,-1)$ & 0.15 & 0.2 & 10 \\
$(-1,0,1)$ & 0.05 & 0.2 & 30 \\
$(1,0,1)$ & 0.15 & 0.2 & 30 \\
$(0,-1,-1)$ & 0.1 & 0.15 & 10 \\
$(0,1,-1)$ & 0.1 & 0.25 & 10 \\
$(0,-1,1)$ & 0.1 & 0.15 & 30 \\
$(0,1,1)$ & 0.1 & 0.25 & 30 \\
$(0,0,0)$ & 0.1 & 0.2 & 20 \\
$(0,0,0)$ & 0.1 & 0.2 & 20 \\
$(0,0,0)$ & 0.1 & 0.2 & 20 \\
\hline
\end{tabular}

The statistical analysis of data that obtained was shown in Table 2 for absorption at $300 \mathrm{~nm}$. It was shown that $\mathrm{X}_{0}$ and $\mathrm{X}_{1}$ have bigger error than $\mathrm{X}_{2}$. This indicates that the \%extract has bigger contribution to the absorption at $300 \mathrm{~nm}$ than $\mathrm{CuSO} 4$ and sodium citrate concentration.

TABLE II. Coefficient Parameter at Peaks of $300 \mathrm{~nm}$ of the Response Surface Model.

\begin{tabular}{ccccccc}
\hline Intercep & Coef & Std error & $\mathbf{t}$ & $\mathbf{P}>|\mathbf{t}|$ & $\mathbf{0 , 0 2 5}$ & $\mathbf{0 , 9 7 5}$ \\
\hline 1 & $-1,5951$ & 1,493 & $-1,068$ & 0,334 & $-5,433$ & 2,242 \\
$\mathrm{X}_{0}$ & 5,0167 & 8,550 & 0,587 & 0,583 & $-16,962$ & 26,995 \\
$\mathrm{X}_{1}$ & 22,2558 & 12,264 & 1,815 & 0,129 & $-9,269$ & 53,780 \\
$\mathrm{X}_{2}$ & 0,0615 & 0,043 & 1,438 & 0,210 & $-0,048$ & 0,171 \\
$\mathrm{X}_{0}^{2}$ & $-11,9833$ & 28,936 & $-0,414$ & 0,696 & $-86,367$ & 62,400
\end{tabular}




\begin{tabular}{ccccccc}
$\mathrm{X}_{0} \mathrm{X}_{1}$ & $-10,0000$ & 27,801 & $-0,360$ & 0,734 & $-81,465$ & 61,465 \\
$\mathrm{X}_{0} \mathrm{X}_{2}$ & 0,1000 & 0,139 & 0,719 & 0,504 & $-0,257$ & 0,457 \\
$\mathrm{X}_{1}^{2}$ & $-48,2833$ & 28,936 & $-1,669$ & 0,156 & $-122,667$ & 26,100 \\
$\mathrm{X}_{1} \mathrm{X}_{2}$ & 0,1505 & 0,139 & 1,083 & 0,328 & $-0,207$ & 0,508 \\
$\mathrm{X}_{2}{ }^{2}$ & $-0,0020$ & 0,001 & $-2,705$ & 0,043 & $-0,004$ & $-9,75 \times 10^{-5}$ \\
\hline
\end{tabular}

Second order equation with correlation coefficient of 0.955 was obtained and described in Equation (1).

$\mathrm{Y}=(-1,5951)+5,0167 \mathrm{x} 0+22,2558 \mathrm{x} 1+0,0615 \mathrm{x} 2+(-11,9833 \mathrm{x} 02)+(-10,0000 \mathrm{x} 0 \mathrm{x} 1)+$ $0,1000 \times 0 \times 2+(-48,2833 \times 12)+0,1505 \times 1 \times 2+(-0,0019 \times 22)$.

The scatter plot of absorbance experimental data compared to the model that obtained was presented in Figure 6 (a). Figure 7 (b) indicates that the residual plot obtained was spread at unstructured and random points. That presented sufficiency models and no need for transformation to stabilize conditions [18].

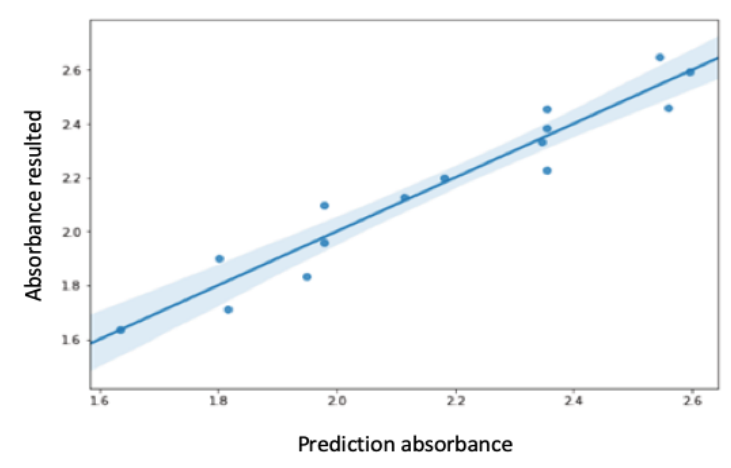

(a)

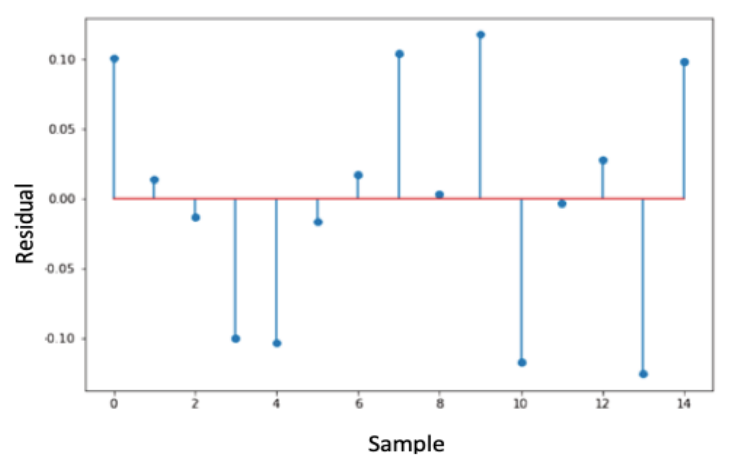

(b)

Figure 6. (a) Absorbance Predictions at The Peak $300 \mathrm{~nm}$, (b) Residual Plot

The model for absorption peak at $800 \mathrm{~nm}$ was presented in Table 3. Based on data obtained in Table 3 , second order equation (2) was obtained, Equation (2). The experimental absorbance data on this study on the results of absorbance predictions were presented in Figure 7 (a). The correlation coefficient of 0.990 was obtained. Figure 7 (b) shows that the residual plot obtained was spread at unstructured and random points. That indicates sufficiency models and no need for transformation to stabilize conditions [18].

TABLE III. Coefficient Parameter at Peaks of $800 \mathrm{~nm}$ of the Response Surface Model

\begin{tabular}{ccccccc}
\hline Intercept & Coef. & Std. error & $\mathbf{t}$ & $\mathbf{P}>|\mathbf{t}|$ & $\mathbf{0 , 0 2 5}$ & $\mathbf{0 , 9 7 5}$ \\
\hline 1 & $-0,2093$ & 0,175 & $-1,196$ & 0,285 & $-0,659$ & 0,240 \\
$\mathrm{X}_{0}$ & 3,2325 & 1,002 & 3,226 & 0,023 & 0,657 & 5,808 \\
$\mathrm{X}_{1}$ & 2,4125 & 1,437 & 1,679 & 0,154 & $-1,282$ & 6,107 \\
$\mathrm{X}_{2}$ & $-0,0035$ & 0,005 & $-0,704$ & 0,513 & $-0,016$ & 0,009 \\
$\mathrm{X}_{0}{ }^{2}$ & $-3,5500$ & 3,391 & $-1,047$ & 0,343 & $-12,267$ & 5,167 \\
$\mathrm{X}_{0} \mathrm{X}_{1}$ & $-1,3000$ & 3,258 & $-0,399$ & 0,706 & $-9,675$ & 7,075 \\
$\mathrm{X}_{0} \mathrm{X}_{2}$ & 0,0110 & 0,016 & 0,675 & 0,529 & $-0,031$ & 0,053 \\
$\mathrm{X}_{1}{ }^{2}$ & $-4,9500$ & 3,391 & $-1,460$ & 0,204 & $-13,667$ & 3,767 \\
$\mathrm{X}_{1} \mathrm{X}_{2}$ & $-0,0030$ & 0,016 & $-0,184$ & 0,861 & $-0,045$ & 0,039 \\
$\mathrm{X}_{2}{ }^{2}$ & 0,0001 & $8,48 \times 10^{-5}$ & 1,224 & 0,276 & $-0,000$ & 0,000 \\
\hline
\end{tabular}


Second order equation with correlation coefficient of 0.955 was obtained and described in Equation (2).

$\mathrm{Y}=0,2093+3,2325 \mathrm{x} 0+2,4125 \mathrm{x} 1+(-0,0035 \mathrm{x} 2)+(-3,55 \mathrm{x} 02)+(-1,3 \times 0 \mathrm{x} 1)+0,011 \mathrm{x} 0 \mathrm{x} 2+(-$ $4,95 \times 12)+(-0,003 \times 1 \times 2)+0,0001 \times 22$

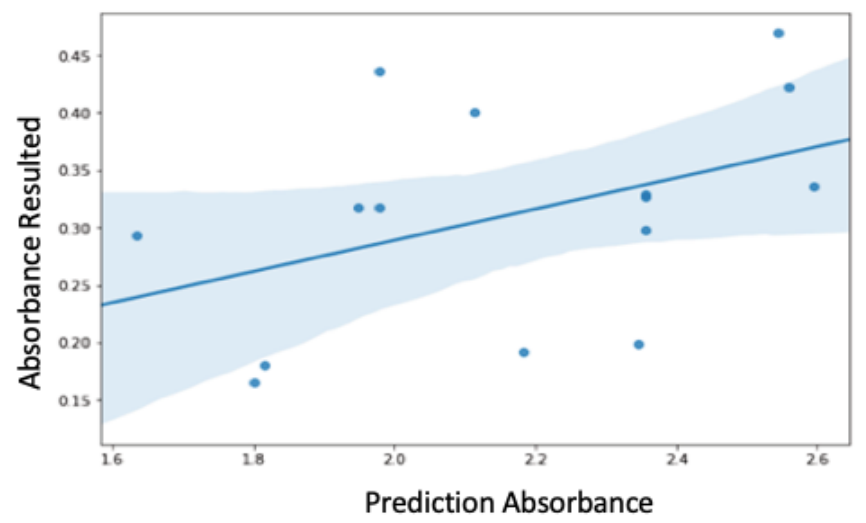

(a)

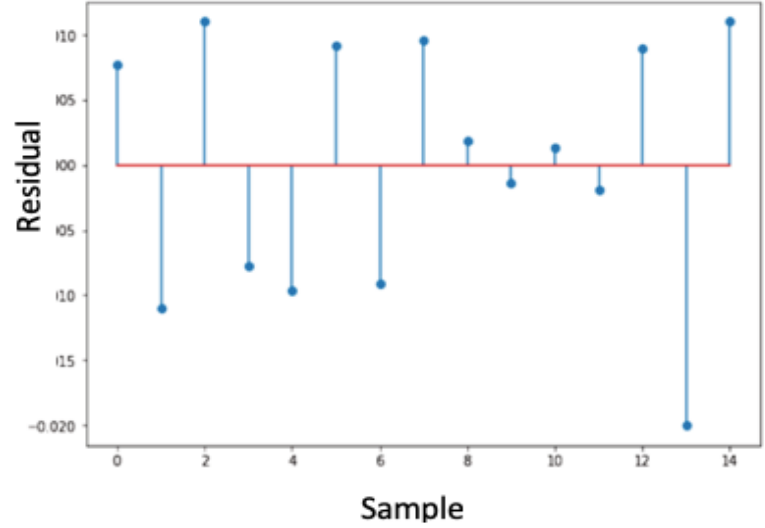

(b)

Figure 7. (a) Absorbance Predictions at The Peak $300 \mathrm{~nm}$, (b) Residual Plot

The RSM shows the effect of variables variation and its interaction. The three-dimensional surface response for absorption peaks at $300 \mathrm{~nm}$ was presented in Figure 8 (a), (b), and (c). The determination of optimum conditions was shown in red contours because at the peak of $300 \mathrm{~nm}$ there was an increase in absorbance. The interaction of the $\mathrm{CuSO}_{4}$ concentration and $\mathrm{Na}_{3} \mathrm{C}_{6} \mathrm{H}_{5} \mathrm{O}_{7}$ concentration on the copper nanoparticles that synthesized was presented in Figure 8 (a). The optimum response was observed at $\mathrm{CuSO}_{4}$ concentrations above $0.11 \mathrm{M}$ and $\mathrm{Na}_{3} \mathrm{C}_{6} \mathrm{H}_{5} \mathrm{O}_{7}$ concentrations above $0.21 \mathrm{M}$. Figure 8 (b) presented the interaction of the $\mathrm{CuSO}_{4}$ concentration and the percent of $\mathrm{C}$. odorata extracts. The optimum conditions was achieved at concentrations of $\mathrm{CuSO}_{4}$ above $0.12 \mathrm{M}$ and percent of $\mathrm{C}$. odorata extract above $22.5 \%$. Figure 8 (c) presented the interaction of $\mathrm{Na}_{3} \mathrm{C}_{6} \mathrm{H}_{5} \mathrm{O}_{7}$ concentration and percent of $\mathrm{C}$. odorata extracts. The optimum condition was achieved at $\mathrm{Na}_{3} \mathrm{C}_{6} \mathrm{H}_{5} \mathrm{O}_{7}$ concentration above $0.23 \mathrm{M}$ and percent of $\mathrm{C}$. odorata extract above $22.5 \%$.

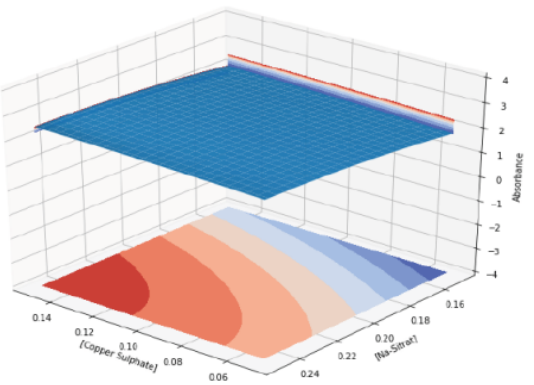

(a)

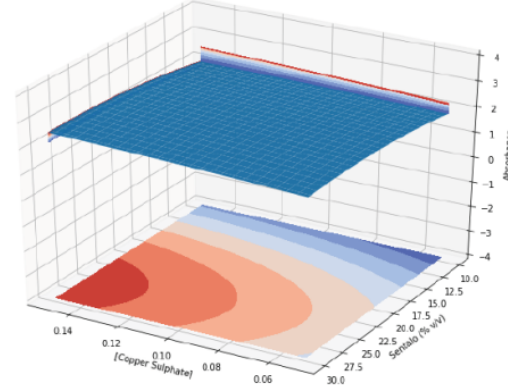

(b)

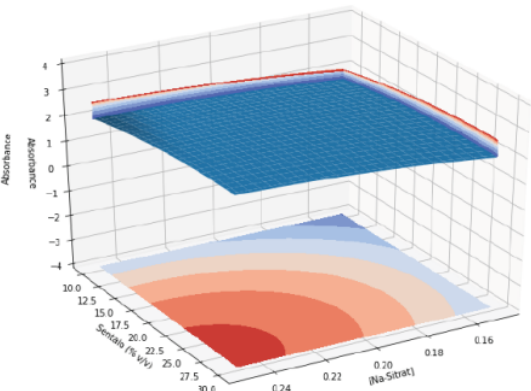

(c)

Figure 8. Response surface of (a) $\mathrm{CuSO}_{4}$ and sodium citrate concentration, (b) $\mathrm{CuSO}_{4}$ concentration and percent extract, and (c) sodium citrate concentration and percent extract.

\section{CONCLUSION}

C. odorata leaf extract has been successfully applied as a stabilizing agent for synthesis of copper nanoparticles. The synthesized copper nanoparticles have rod shapes with an average diameter of 30 nm. Optimization result using Response Surface Methodology Box-Behnken Design obtain that the optimum response was obtained using $\mathrm{CuSO} 4$ concentration of 0.12 to $0.15 \mathrm{M}$, sodium citrate ( $\mathrm{Na3C} 6 \mathrm{H} 5 \mathrm{O} 7$ ) concentrations of $0.22 \mathrm{M}$ to $0.25 \mathrm{M}$, and percent extract $22.5 \%$ to $30 \%$, for absorption 
at $300 \mathrm{~nm}$. The optimum response for absorption at $800 \mathrm{~nm}$ was achieved using CuSO4 of $0.05 \mathrm{M}$ to $0.06 \mathrm{M}$, sodium citrate $(\mathrm{Na} 3 \mathrm{C} 6 \mathrm{H} 5 \mathrm{O} 7)$ concentrations of $0.15 \mathrm{M}$ to $0,25 \mathrm{M}$, and percent extract from $10 \%$ to $22.5 \%$.

\section{Acknowledgment}

The authors were very grateful to The Head of Chemistry Department and The Head of Instrumentation and Analytical Science Laboratory for facility support.

\section{References}

[1] J. Fernando and P. Gurulakshmi," Green Synthesis and Characterization of Copper Nanoparticles and Their Applications,'J. Nanosci. Tech. vol 2, 5, 234-236, 2016

[2] C. Buzzea, I.I. Pacheco and K. Robbie, Bionterphases vol. 2, 4, 2007

[3] SCENIHR, "The Appropriateness of Existing Methodologies to Assess The Potential Risks Associated with Engineered and Adventitious Products of Nanotechnologies", European Commission, Health and Consumer Protection Directorate-General, 9-16, 2006

[4] P. Christian, F.V.D. Kammer, M. Baalousha and T. Hofmann," The ecotoxicology and chemistry of manufactured nanoparticles," Ecotoxicology vol. 17, 5, 326-343, 2008

[5] S. Jain, A. Jain, P. Kachhawah and V. Devra," Synthesis and size control of copper nanoparticles and their catalytic application," Trans. Nonferrous Met. Soc. China vol. 25, 12, 3995-4000, 2015

[6] M.I. Din and R. Rehan," Synthesis, Characterization, and Applications of Copper Nanoparticles,"Anal. Letters vol. 50, 1, 50-62, 2016

[7] S. Fatma, P. Kalainila, E. Ravindran, and S. Renganathan," Green Synthesis of Copper Nanoparticle From Passiflora Foetida Leaf Extract and Its Antibacterial Activity,"Asian. J. Pharm. Clin. Res. vol. 10, 4, 7983, 2017

[8] T. P. Raju, B. R. Narender, and V. R. Krishna, J. Sci. Res. Pharm vol. 5, 2, 21-22, 2016

[9] G. Pal, P. Rai, and A. Pandey,"Green Synthesis,Characterization and Applications of Nanoparticles", Shukla and Iravani, India, pp. 30-35, 2019

[10] N. Nagar and V. Devra," Green synthesis and characterization of copper nanoparticles using Azadirachta indica leaves," J. Mat. Chem. Phys. vol. 213, 44-51, 2018

[11] A. C. Akinmoladun, E. O. Ibukun, and I. A. Dan-Ologe," Phytochemical Constituents And Antioxidant Properties Of Extracts From The Leaves Of Chromolaena odorata," J. Sci. Res. Essay vol. 2, 191-194, 2007

[12] M. Hadi, Pembuatan Kertas Anti Rayap Ramah Lingkungan dengan Memanfaatkan Ekstrak Daun Kirinyuh (Eupatorium odoratum),"BIOMA vol. 6, 12-18, 2008.

[13] J. B. Fathima, A. Pugazhendhi, M. Oves, and R. Venis,"Synthesis of eco-friendly copper nanoparticles for augmentation of catalytic degradation of organic dyes,"J. Mol. Liq. vol. 260, 1-8, 2018

[14] M. Gopinath, R. Subbaiya, M. M. Selvam, and D. Suresh," Synthesis of Copper Nanoparticles from Nerium oleander Leaf aqueous extract and its Antibacterial Activity," Int. J. Curr. Microb. App. Sci. vol.3, 814-818, 2014

[15] A. P. Ramos, Nanochar. Tech, 99-110, 2017

[16] D. Mott, J. Galkowski, L. Wang, J. Luo, and C. J. Zhong," Synthesis of Size-Controlled and Shaped Copper Nanoparticles," Langmuir vol. 23, 5740-5745, 2007

[17] Y. Bai, G. Saren, and W. Huo," Response surface methodology (RSM) in evaluation of the vitamin C concentrations in microwave treated milk," J. Food Sci. Tech. vol. 52, 4647-4651, 2014

[18] W. Sibanda and P. Pretorius, Net. Model. Anal. Health Infor. Bioinfor. vol. 2, 137-146, 2013

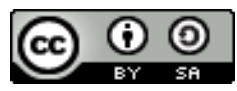

Jurnal IJCA is licensed under aÂ Creative Commons Attribution ShareAlike 4.0 